\title{
Mudar de Perspetiva: A Dimensão Transnacional do Cinema Português Contemporâneo Iván Villarmea Álvarez ${ }^{1}$
}

O termo 'cinema transnacional' foi criado há cerca de vinte anos para identificar aqueles filmes que mostravam os efeitos da globalização económica através da sua forma, do seu conteúdo e mesmo da sua própria conceção como produto audiovisual. Este conceito permitiu superar a dicotomia entre cinema nacional - entendido como cinema próprio - e cinema estrangeiro - entendido como cinema dos outros - pelo que, em poucos anos, foi aceite massivamente pela crítica académica, como comprovam os trabalhos de Lu (1997), Nestingen e Elkington (2005), Ezra e Rowden (2006) ou Durovicová e Newman (2009). Este sucesso, porém, também provocou uma banalização no emprego deste termo que derivou, anos depois, na sua desvalorização como conceito operativo, como aponta a teórica dinamarquesa Mette Hjort:

The term 'transnational' has assumed a referential scope so broad as to encompass phenomena that are surely more interesting for their differences than their similarities. As a result, and quite against the intentions of those who use it, 'transnational' ends up playing a strangely homogenizing role that brings to mind Hegel's sarcastic reference to the 'night in which all cows are black' as a response to thinking in which conceptual distinctions are effaced rather than properly developed $(2009,13)$.

$\mathrm{O}$ artigo a que pertence este excerto tinha como objetivo redefinir o significado deste termo através de uma série de exemplos que davam forma ao que Hjort denominou "a tipology of cinematic transnationalisms" $(2009,15-30)^{2}$. Este esforço por dotar este conceito de um sentido preciso terá continuidade em publicações posteriores, como o artigo inaugural do primeiro número da revista científica Transnational Cinemas, no qual Will Higbee e Song Hwee Lim reivindicavam a prática de um "transnacionalismo crítico" (2010, 7-21), ou no texto "Deconstructing and Reconstructing 'Transnational Cinema", no qual Deborah Shaw comentava até quinze categorias diferentes ligadas ao conceito de cinema transnacional, numa tentativa de

\footnotetext{
${ }^{1}$ Universidad Estatal de Milagro (UNEMI), Milagro, Guayas, Ecuador.

${ }^{2}$ Esta tipologia seria formada pelas seguintes categorias: "epiphanic transnationalism", "affinitive transnationalism", "milieu-building transnationalism", "opportunistic transnationalism", "cosmopolitan transnationalism", "globalizing transnationalism", "auterist transnationalism", "modernizing transnationalism" e "experimental transnationalism". As três mais importantes para este artigo serão, em concreto, "epiphanic transnationalism", "affinitive transnationalism" e "cosmopolitan transnationalism".
} 
distinguir entre "industrial practices, working practices, aesthetics, themes and approaches, audience reception, ethical questions, and critical reception" $(2013,51)^{3}$. Todo este trabalho teórico conseguiu, por um lado, o esclarecimento do significado deste termo; e por outro lado, a ampliação dos casos nos quais pode ser utilizado com propriedade, já que as distintas tipologias e categorias criadas por Hjort e Shaw fornecem aos críticos exemplos concretos que podem extrapolar a outras situações, filmes e cineastas. Neste contexto, o propósito deste artigo é explorar a hipotética dimensão transnacional de um cinema tão aparentemente fechado sobre si mesmo como o cinema português, para inverter, desta forma, a perspetiva com a que a crítica, a história e os estudos de cinema têm abordado tradicionalmente esta cinematografia. Portanto, este texto não vai analisar aqueles elementos que identificam e individualizam o cinema português defronte de outros cinemas nacionais dentro da geopolítica do cinema, senão outros elementos que permitem o diálogo entre cineastas, públicos e cinematografias para facilitar, em última instância, a integração de qualquer cinema nacional - neste caso, do cinema português - dentro de alguma das diferentes redes que dão forma ao sistema audiovisual contemporâneo.

\section{O Cinema Português como Cinema Nacional}

Num dos textos mais influentes sobre o que foram os cinemas nacionais até aos anos oitenta, o crítico britânico Andrew Higson distinguia entre duas formas opostas para identificar as particularidades de um determinado cinema nacional: a primeira partia de uma perspetiva endógena, que entende a nação em relação consigo mesma, com a sua história, a sua tradição e os seus signos de identidade comum; a segunda, pelo contrário, adotava uma perspetiva exógena para afirmar a particularidade de um cinema nacional mediante as suas diferenças com respeito a outros cinemas nacionais (1989, 3646). O cinema português costuma ser definido da primeira forma, como uma expressão dos valores e elementos ligados ao conceito de "portugalidade" ${ }^{4}$, porque desse modo o próprio cinema permite estabelecer uma imagem da nação, percebida como autorrepresentação, que contribui para afirmar determinados discursos culturais ou ideo-

\footnotetext{
${ }^{3}$ Essas quinze categorias seriam "transnational modes of production, distribution and exhibition", "transnational modes of narration", "cinema of globalisation", "films with multiple locations", "exilic and diasporic filmmaking", "film and cultural exchange", "transnational influences", "transnational critical approaches", "transnational viewing practices", "transregional / transcommunity films", "transnational stars", "transnational directors", "the ethics of transnationalism", "transnational collaborative networks" e, por último, mesmo "national films" (Shaw 2013, 47-66).

${ }^{4}$ Sobre este conceito, será útil consultar as recentes teses de doutoramento de Vítor de Sousa, intitulada Da "portugalidade" à lusofonia (2015, Universidade do Minho), e de Daniel Ribas, intitulada Retratos de Família: A Identidade Nacional e Violência em João Canijo (2014, Universidade de Aveiro e Universidade do Minho).
} 
lógicos promovidos, às vezes, desde o próprio poder. A definição de cinema português por oposição a outros cinemas nacionais, no entanto, não é tão frequente nem tão útil - ainda menos no presente pósmoderno e globalizado - porque nesse caso a única oposição evidente é a que confronta ao cinema industrial de grande orçamento quer americano, quer europeu - com o cinema de baixo orçamento, denominado também cinema "pobre" ou cinema artesanal. Os produtores e cineastas portugueses são plenamente conscientes das suas limitações económicas e, portanto, da sua condição de artesãos do cinema (ver Urbano em Martins \& Cipriano 2013, 351), mas esta circunstância não implica uma particularidade que possa diferenciar claramente o cinema português de outros cinemas nacionais de baixo orçamento procedentes de Europa, Ásia ou América Latina. A situação, de facto, é a contrária: uma das formas mais habituais para reivindicar a alteridade de um determinado cinema nacional funciona aqui à inversa, isto é, como um meio para encontrar dinâmicas e elementos similares noutras latitudes.

Um trabalho recente que, de forma indireta, identifica desde uma perspetiva endógena algumas das características que definem ao cinema português contemporâneo como um cinema nacional é o artigo "Objectos únicos e diferentes. Por uma nova cultura organizacional do cinema português contemporâneo", escrito por João Maria Mendes dentro do volume coletivo Novas \& Velhas Tendências no Cinema Português Contemporâneo (2013, 74-137). Nesse texto, Mendes é muito crítico em relação às inércias herdadas em matéria de produção dos tempos do Novo cinema português, porque considera que limitaram o desenvolvimento de uma cultura organizacional mais eficiente, mesmo mais profissional, ao converter umas determinadas escolhas estéticas - as mesmas que, no estrangeiro, identificam o cinema português como um cinema nacional - numa forma de trabalho.

Entre os traços gerais que ele descreve, há dois que reforçam precisamente a permanência do cinema português dentro do paradigma do cinema nacional: a sua dependência económica dos subsídios públicos de apoio à produção cinematográfica, já que o financiamento obtido através de produtoras estrangeiras é marginal com respeito às cifras de investimento estatal; e a sua fraca circulação internacional, quer nos mercados europeus, americanos ou asiáticos (Mendes $2013,94,102$ ). Este modelo impossibilita que os filmes portugueses entrem na primeira categoria analisada por Deborah Shaw: os modos de produção, distribuição e exibição transnacional ${ }^{5}$. Esta tendência responde às transformações que os processos globais provocaram no funcionamento interno do sistema cinematográfico mundial: no primeiro momento, nos anos oitenta e noventa do passado século,

\footnotetext{
5 "This category relates to financial questions: funding for filmmaking through coproductions; the question of niche markets; the policies of distribution and exhibition companies, and the marketing of films to global audiences" (Shaw, 2013, 52)
} 
houve uma fase de dispersão da produção de que se aproveitaram muitos cinemas nacionais para vir à tona; para depois, a partir do novo milénio, entrar numa fase contrária, de concentração da produção, que obrigou a que esses mesmos cinemas nacionais tivessem de desenvolver estratégias de colaboração e coprodução para manter os seus níveis de bilheteira e de visibilidade. Nestas circunstâncias, a questão é como pode o cinema português encontrar o seu lugar dentro do sistema audiovisual contemporâneo se permanece fora destes circuitos de financiamento e distribuição transnacionais. Deve então continuar a reivindicar uma determinada ideia, já fossilizada, do que se supõe que deva ser a sua tradição nacional, sem que esta possa mudar com os tempos? A resposta, segundo Mendes, seria a vontade do cinema português de ser percebido no estrangeiro como parte do que se poderá designar por world cinema:

Dados os seus meios e as competências disponíveis, e dada a cultura organizacional característica do cinema português, este não pode pretender (e talvez por isso maioritariamente não queira) fazer parte do mainstream cinematográfico e dos seus géneros, mas antes se situa entre águas difíceis de distinguir, as do cinema de autor, as do cinema 'de arte e ensaio' e as do cinema independente. Mas gostaria de se ver classificado - se ultrapassasse os problemas de qualidade técnica das suas histórias e conteúdos, dos seus actores, dos seus modos de produção e de realização - na categoria que um David Bordwell designa por international art films, ou que [Shohini] Chaudhuri designa por World Cinema. Tais categorias - cinema de autor, de arte e ensaio, independente e aproximável do international art film ou do World Cinema - são consctructs genéricos e aproximativos, mas a sua articulação num conjunto de significados heterogéneos tornou-se o referente imaginário do cinema português contemporâneo: ele deseja, confusamente, ser tudo isto ao mesmo tempo - um borderliner, um habitante de fronteiras $(2013,97)$.

$\mathrm{O}$ interesse dos cineastas portugueses em associar os seus filmes a estas categorias marca uma mudança na própria construção interna do conceito "cinema português", já que muitos cineastas, sem romper com a tradição nacional nem renunciar a uma hipotética filiação com ela, começaram há uma ou duas décadas a procurar referentes, paralelos ou simplesmente inspiração noutras cinematografias nacionais ou regionais.

Mendes $(2013,105)$ dá como exemplos concretos as cinematografias grega e iraniana, assim como também, de uma forma mais geral, uma parte das cinematografias europeias, asiáticas e sulamericanas, com as quais o cinema português "partilha, mesmo que imaginariamente, a 'síndrome de pobreza', mas também a reivindicação da sua 'originalidade' e 'qualidade', e por vezes uma ideologia de 'resistência'”.

Este deslocamento desde uma autodefinição do cinema português em relação a si próprio para uma definição em relação a outras cinematografias - atenção, relações de semelhança e de proximidade, 
não relações de oposição - tem a ver com a evolução recente do conceito de identidade, que segundo o filósofo francês Jean-Luc Nancy passou de construir-se a partir da primeira pessoa do singular para colocar a ênfase na primeira pessoa do plural, porque não pode haver existência individual sem coexistência com um outro: qualquer "eu", portanto, tem sempre um sentido social, expressa a relação de interdependência entre um sujeito e uma comunidade, estabelece uma comunicação bilateral ou mesmo multilateral (Nancy 1996). Se agora aplicamos esta lógica às dinâmicas da globalização, podemos encontrar uma interdependência similar entre o local e o global, porque algo é local em relação àquilo que é global, mas também porque desde uma perspetiva global pode interessar enfatizar uma determinada particularidade, como adverte o sociólogo britânico Roland Robertson $(1995,26)$ : "What is called local is in large degree constructed on a trans- or super-local basis. In other words, much of the promotion of locality is in fact done from above or outside".

Esta última ideia abre uma nova possibilidade para definir o cinema português como cinema nacional que não dependeria dos discursos gerados pelos cineastas portugueses. Desde esta perspetiva, o cinema português poderia ser uma invenção do exterior, da crítica e dos distribuidores estrangeiros, pelo menos desde os anos oitenta, como já afirmaram pesquisadores como Tiago Baptista ou o próprio João Maria Mendes:

A ideia de 'cinema nacional' que antes unira realizadores, público e críticos no que parecera a melhor maneira de promover a cultura portuguesa e competir com o cinema estrangeiro, acabou por reduzir o cinema português a um 'nicho de mercado' no seio do 'cinema de arte' europeu - posição que encontrou na categoria de 'escola portuguesa', imposta a partir do estrangeiro, a sua expressão mais acabada (Baptista 2009, 309)

O cinema português é singularmente visto, por uma parte da sua recepção e da crítica, como um 'género' ou um 'quase-género', e essa classificação inspira-se em Georges Sadoul, que entendeu, na sua história do cinema, exercitar um vasto olhar dedicado às 'cinematografias nacionais', suas caracterizações e idiossincrasias. Em determinado momento do 'pós-Cinema Novo', parte da crítica internacional, sobretudo francófona, chegou a falar de uma école portugaise, a despeito da variedade das experiências autorais que nela se singularizavam (Mendes 2013, 502).

Quando a crítica internacional põe a sua atenção num determinado cinema nacional - quer o romeno, quer o filipino, para nomear apenas dois casos célebres na década passada - não está sempre a chamar à atenção sobre o caráter representativo desse cinema com respeito à sua correspondente nação, senão que às vezes está apenas a definir estes cinemas nacionais como cinemas estrangeiros ou exóticos para o público cinéfilo internacional que muitas vezes coincide com o público nacional de países como França, Reino Unido ou Estados Unidos. "[T]he phenomenon of the art house", es- 
creve a teórica indiana Jigna Desai $(2004,37)$, "is based on positioning 'foreign' films as ethnographic documents of 'other' (national) cultures and therefore as representatives of national cinemas". Nestes casos, a identificação de um cinema nacional é produto da sua circulação internacional, pelo que não se pode entender este conceito como uma entidade autónoma e isolada, sobretudo se queremos que continue a ser operativo no presente.

\section{Cineastas Nacionais, Cineastas Globais}

A crítica internacional sente-se à vontade no circuito de festivais de cinema, onde experimenta a ilusão de conhecer o conjunto da produção cinematográfica mundial de um determinado ano. As secções oficiais dos grandes festivais, como Cannes, Toronto, Veneza, Berlim ou Locarno, desejam funcionar como uma sinédoque do cinema mais relevante do presente, embora sejam o resultado de uma combinação de interesses estéticos, económicos, políticos e ideológicos. A estreia mundial de um filme português em algum destes eventos implica, como explica o cineasta João Pedro Rodrigues, "ter meio caminho andado e a partir daí é uma espécie de bola de neve" (em Sousa Dias, Pereira e Jácome 2013, 270).

O problema, no entanto, reside na elevada concorrência e na arbitrariedade das decisões de programação, que podem seguir um sistema de quotas nacionais para reproduzir uma certa ideia da geopolítica do cinema. A lógica dos festivais pode ser assim injusta e reducionista, até ao ponto de simplificar o cinema produzido num determinado país aos nomes dos suspeitos do costume, como adverte o crítico australiano Tom O'Regan (2004: 521): "For the vast bulk of countries, which are small- or medium-sized in population terms or are comparatively impoverished in terms of film-production funding and circulation, we can be looking at 'one-person' film industries". Por este motivo, a perceção internacional do cinema português esteve limitada, durante muito tempo, ao trabalho de Manoel de Oliveira, um cineasta considerado, simultaneamente, como autor nacional e como autor global. Esta condição quase anfíbia, que o situou numa posição intermédia entre o local e o global, é consequência de uma das maiores virtudes da sua obra: ser "um cinema feito de olhos postos no estrangeiro, mas sem nunca virar as costas à realidade cultural do seu país de origem”, segundo a definição de Tiago Baptista (2009, 314).

O caminho inaugurado por Manoel de Oliveira seria depois percorrido por outros cineastas mais novos, como Paulo Rocha, João César Monteiro, Pedro Costa ou Miguel Gomes. O facto de que este sucesso anteceda a distribuição dos filmes nas próprias salas nacionais confirma a tese, defendida por Baptista, de que o "autorismo nacional" foi "construído a partir do estrangeiro" (2009: 310). A dedução lógica que se pode fazer a partir desta ideia é que os cineastas portugueses precisam primeiro afirmar-se como autores globais para depois serem 
reconhecidos como autores nacionais. O modelo a imitar seria, portanto, o do autor global, segundo foi descrito pelo historiador do cinema Thomas Elsaesser (2005: 499) há mais duma década:

$\mathrm{He} / \mathrm{she}$ must be able to attract attention on the festival circuit, but otherwise need not be capable of captivating the broad general cinema-going public. The auteur's natural home would then be world cinema, rather than the old national cinemas, thereby signaling a cinema that, while perhaps not suited for the national market, does well in international export markets, reaches the secondary markets of television or even the mass marketing of DVD releases with their vast network of internet-based fan sites and DVD reviews. A world cinema auteur thus can reach across many different countries, and under different reception conditions, can find a niche market with a dedicated audience.

Um número elevado de autores globais procedentes de um mesmo país - por pequeno que seja - ajuda os cinemas nacionais a ocupar uma posição de poder nos processos de transferência cultural. Estes processos, estudados pelo semiótico russo Yuri M. Lotman, são o resultado das relações de troca estabelecidas entre diferentes culturas, que costumam desenvolver-se em cinco etapas sucessivas: na primeira, os produtos culturais importados mantêm a sua estranheza e são mais valorizados que os produtos autóctones; na segunda, começa uma lenta reestruturação entre a cultura importada e a cultura local, no que aumenta a apreciação dos produtos autóctones; na terceira, essa reestruturação evolui numa fusão onde ainda é possível distinguir os modelos e valores importados; na quarta, a influência estrangeira fica definitivamente diluída na cultura local; e na quinta, a cultura recetora evolui até se converter numa cultura transmissora, capaz de influenciar outras culturas através da exportação dos seus próprios produtos culturais (Lotman 1990: 146).

Nas últimas décadas, um dos poucos cinemas nacionais que atravessou estas cinco etapas, passando do estádio de cultura recetora ao de cultura transmissora, foi o cinema produzido em Coreia do Sul, que em apenas quinze anos conseguiu posicionar vários dos seus cineastas - Bong Joon-ho, Hong Sang-soo, Im Kwon-taek, Kim Kiduk, Lee Chang-dong, Park Chan-wook, entre outros - dentro do seleto grupo dos autores globais.

O caso português é bem diferente. Longe do modelo coreano, que assenta na existência de uma industrial audiovisual e de um mercado interior muito fortes, o cinema português percorreu três ou quatro etapas do processo, mas a sua fraqueza económica não lhe permite ainda atingir o quinto e último nível. A oposição entre as comédias à portuguesa e o cinema clássico de Hollywood dos anos trinta, quarenta e cinquenta seria um bom exemplo da primeira etapa, que permite a introdução de novos formatos e paradigmas críticos numa determinada cultura para iniciar o seu posterior processo de regeneração. As tentativas do Novo cinema português de aproximar o 
cinema português à modernidade europeia dos anos sessenta e setenta implicaria a entrada na segunda etapa, na qual o conteúdo seria local e a forma internacional. Os filmes que Manoel de Oliveira realiza a partir da Tetralogia dos Amores Frustrados, assim como o trabalho de outros cineastas modernos associados à Escola portuguesa, supõem a entrada na terceira etapa. Por último, a consolidação do cinema pós-moderno no novo milénio permite reconhecer a quarta etapa, mas os trabalhos dos poucos autores globais portugueses que há no presente, entre os quais Pedro Costa e Miguel Gomes, ainda não tiveram uma repercussão tão generalizada para que seja possível identificar o cinema português com uma cultura transmissora.

\section{Influências Transnacionais: O Cinema como Pátria}

A aceleração das dinâmicas de troca e dos processos de transferência cultural a partir dos anos oitenta provocaram que o paradigma dos cinemas nacionais ficasse obsoleto na transição do milénio. A causa principal desta mudança de paradigma, segundo argumentam Elizabeth Ezra e Terry Rowden, é que as estruturas epistemológicas e referenciais que os filmes contemporâneos requerem para ser descodificados estão a perder as particularidades nacionais e culturais que tiveram no passado $(2006,4)$. Esta explicação surge depois da quebra do paradigma anterior, embora haja outros críticos, começando pelo próprio Andrew Higson, que procuram as causas desta quebra nos defeitos de construção do próprio paradigma. Num exercício de autocrítica muito louvável com respeito ao seu trabalho prévio sobre os cinemas nacionais, Higson $(2006,20)$ reconhece que "the concept of national cinema is hardly able to do justice either to the internal diversity of contemporary cultural formations or to the overlaps and interpenetrations between different formations". Para além disso, o próprio conceito de cinema nacional só faz sentido num contexto estável e estático, que não admite evolução nenhuma, pelo que qualquer definição do que possa ser um cinema nacional fica restringida a um momento histórico concreto:

The problem with this formulation is that it tends to assume that national identity and tradition are already fully formed and fixed in place. It also tends to take borders for granted and to assume that those borders are effective in containing political and economic developments, cultural practice and identity. In fact of course, borders are always leaky and there is a considerable degree of movement across them (even in the most authoritarian states). It is in this migration, this border crossing, that the transnational emerges. Seen in this light, it is difficult to see the indigenous as either pure or stable. On the contrary, the degree of cultural cross-breeding and interpenetration, not only across borders but also within them, suggests that modern cultural formations are invariably hybrid and impure (Higson 2006, 18-19). 
A sociedade portuguesa contemporânea é herdeira de todas as suas formas anteriores - a sociedade autoritária do Estado Novo, a sociedade militante da Revolução dos Cravos, a sociedade consumista da III República, etc. - e muda constantemente como resultado do seu encontro com a história. O cinema português, em paralelo, reflete o imaginário destas sociedades, onde há sempre permanências do passado e influências do estrangeiro. Por este motivo, os cineastas mais novos, especialmente aqueles abertamente pós-modernos, trabalham na interseção entre o cinema nacional - a herança da Escola portuguesa - e o cinema transnacional - a influência de referentes e companheiros de geração que formam "uma rede arquipelágica de empatias internacionais relativamente desenraizadas", nas palavras de João Maria Mendes (2013, 543), "cujos membros se sentem próximos uns dos outros independentemente das suas proveniências ou inscrições regionais". Nesta deriva, a filiação com a Escola portuguesa é apenas uma possibilidade estética entre muitas outras que depende dos gostos pessoais e da educação cinéfila de cada cineasta. A cinefilia, definida na sua versão pós-moderna pelo académico norteamericano David Desser $(2003,528)$ como "the ability and necessity of acknowledging the intertextual chain of references, borrowings, and reworkings", está de facto na base de duas das categorias do cinema transnacional analisadas por Deborah Shaw: as influências transnacionais e as aproximações críticas transnacionais ${ }^{6}$. Esta autora reforça a ideia de que nenhum cinema nacional pode existir numa situação de completo isolamento, sobretudo num momento histórico marcado pela crescente interconexão e interdependência entre sistemas económicos, culturais e sociais.

Alguns exemplos muito evidentes de cineastas-cinéfilos dentro do cinema português contemporâneo seriam Pedro Costa, Manuel Mozos, João Pedro Rodrigues, Miguel Gomes ou João Nicolau. O caso particular de Gomes é tão paradigmático que Paulo Cunha chegou a escrever há dois anos um texto sobre a sua obra titulado, precisamente, "Miguel Gomes, el cinéfilo". Nessas páginas, Cunha (2014, 108133) fazia um percurso por algumas das referências cinéfilas que apareciam nos seus filmes anteriores ao projeto As Mil e Uma Noites (2015), e os resultados não podiam ser mais diversos em termos temporais, nacionais, estilísticos e genéricos: A Cara que Mereces (2004), por exemplo, contém citações e referências de Snow White and the Seven Dwarfs (1937), The Wizard of Oz (1939, Victor Fleming) e da obra do cineasta norte-americano Wes Anderson; Aquele Querido Mês de Agosto (2008) atualiza a tradição portuguesa da ficção documental, representada por Acto de Primavera (1963, Manoel de Oliveira) e Nós por cá Todos Bem (1978, Fernando Lopes), num momento no que este género experimenta uma forte renovação

\footnotetext{
6 "These categories assume intertextuality in that every film made has been consciously or unconsciously shaped by pre-existing cultural products from all over the world" (Shaw 2013, 58).
} 
internacional com títulos como Entre les murs (2008, Laurent Cantet), 24 City (2008, Jia Zhang-ke), Alamar (2009, Pedro GonzálezRubio), Le quattro volte (2010, Michelangelo Frammartino) ou Todos vós sodes capitáns (2010, Oliver Laxe); e Tabu (2012, Miguel Gomes), por último, inclui referências explícitas a Tabu, a Story of the South Seas (1931, Friedrich Murnau), Vivre sa vie: Film en douze tableaux (1961, Jean-Luc Godard), Out of Africa (1985, Sydney Pollack) e Paraíso Perdido (1995, Alberto Seixas Santos), entre outros filmes.

O trabalho de reconhecimento destas referências forma parte dum jogo que os cineastas pós-modernos estabelecem com o seu público, embora Gomes não se limite a acumulá-las sem intervir nelas, mas processa-as, transforma-as e integra-as dentro do seu próprio universo criativo, seguindo o modelo popularizado por cineastas norte-americanos como David Lynch, Todd Haynes, Quentin Tarantino, Paul Thomas Anderson ou Guy Maddin.

Este jogo de reconhecimento de referências serve mesmo para explicar o dispositivo estético adotado durante a segunda parte de $\mathrm{Ta}$ bu. Assim, a frase "Aurora tinha uma fazenda em África no sopé do Monte Tabu" (Tabu, 2012, 00:50:10-00:50:32) remete a uma linha equivalente de Out of Africa: "I had a farm in Africa at the foot of the Ngong Hills”. A sua função narrativa é idêntica - as duas frases dão início ao relato de um tempo passado -, mas Gomes aproveita o reconhecimento por parte dos espectadores desta citação para dar uma dica sobre a origem das imagens que vamos ver a seguir. A frase em questão é pronunciada pelo personagem de Gian Luca Ventura, o antigo amante de Aurora, diante de Pilar e Santa, duas mulheres de meiaidade que sabemos que gostam muito dos relatos cinematográficos Pilar vai várias vezes ao cinema durante a primeira metade de Tabu - e literários - Santa lê Robinson Crusoe (Defoe 1719) para as suas aulas de educação para adultos. A cara de incredulidade que apresenta Pilar depois de ouvir essa frase sugere que a sua personagem também reconhecera a referência a Out of Africa, de forma que as imagens que veremos a partir de então poderão ser o produto da sua imaginação cinéfila, alimentada por títulos clássicos - e estrangeiros - como $\mathrm{Mo}$ gambo (1953, John Ford) ou Hatari! (1962, Howard Hawks). Nesta sequência, a cinefilia de Gomes projeta-se sobre a cinefilia da sua personagem, e apela também à cinefilia dos espectadores sem marcar nenhuma fronteira nacional ou cultural. Portanto, a operação de pôr em imagens a paixão de Aurora e Gian Luca combina vários elementos transnacionais: um autor global que põe uma personagem portuguesa a imaginar um continente alheio - África - a partir de referentes cinéfilos predominantemente norte-americanos.

João Pedro Rodrigues e João Rui Guerra da Mata levam ainda mais longe este jogo de referências transnacionais em A Última Vez Que Vi Macau (2012), um filme que é muitos filmes ao mesmo tempo: um documentário sobre a cidade de Macau, um autorretrato urbano de Guerra da Mata, uma autoficção, um thriller neo-noir, um 
filme fantástico, um filme de catástrofes, e mesmo uma reescrita pósmoderna do filme Macao (1952, Josef von Sternberg e Nicholas Ray). O próprio título é um trocadilho, porque pode fazer alusão à última vez que Guerra da Mata - quer o cineasta, quer o protagonista desta autoficção - viu Macau, a cidade, ou Macao, o filme. A fascinação pelo trabalho de Josef von Sternberg e Nicholas Ray leva a Rodrigues e Guerra da Mata a reproduzir a sua iconografia com uma vontade caligráfica, mas com uns interesses completamente diferentes. Por exemplo, a personagem a que Guerra da Mata dá voz, com uma dicção muito similar à dos detetives particulares dos films noirs dos anos quarenta, chega à cidade por mar, como Julie Benson e Nick Cochram, as personagens que interpretavam respetivamente Jane Russell e Robert Mitchum em Macao. Ele vai ao encontro da sua amiga Candy, que trabalha como cantora de night club - mais uma vez, da mesma forma que Julie - mas só encontra os seus rastos: em concreto, um sapato e umas meias-calças - os mesmos objetos que Julie atirava e que atingiam Nick. Por último, os dois filmes situam uma das suas sequências mais importantes - a morte e o desaparecimento de uma personagem - nas docas de Macau. Todas estas coincidências, que só podem ser voluntárias, ajudam o público e a personagem de Guerra da Mata a navegar entre o passado e o presente: o cineasta tem explicado em várias apresentações do filme ${ }^{7}$ que a cidade que ele conheceu na sua infância, nos anos setenta, tinha mais parecenças com a Macau imaginária de Sternberg e Ray do que com a cidade que ele encontrou quarenta anos depois. Neste sentido, por estranho que pareça, a referência cinéfila a um filme estrangeiro rodado completamente em estúdio, longe do próprio território, resulta mais próxima, e aparentemente mais fiel, às suas recordações emocionais.

\section{Transnacionalismos Epifánico, por Afinidade e Cosmopolita}

Os elementos transnacionais que aparecem em A Última Vez Que Vi Macau são mais complexos e profundos do que um simples jogo de reconhecimento de referências. Este filme está concebido a partir do confronto entre o passado colonial e o presente pós-colonial de Macau, uma contradição onde a personagem de Guerra da Mata é um sujeito deslocado, porque apenas pode reconhecer os seus locais através da memória. A sua desorientação é o resultado das transformações urbanas e culturais de Macau, uma cidade que aproveita o seu património colonial como anúncio turístico enquanto enche as suas ruas de símbolos chineses e, sobretudo, capitalistas. O relato da cidade mudou por completo, e só um ex-colono como Guerra da Mata parece preocupado pelo desaparecimento da herança portuguesa, já que implica o desaparecimento simultâneo do seu passado como in-

\footnotetext{
${ }^{7}$ Um exemplo concreto seria no debate posterior à projeção de A Última Vez Que Vi Macau no III Encontro Anual da AIM, que aconteceu a 10 de maio de 2013, em Coimbra.
} 
divíduo. A progressiva tomada de consciência da sua condição de sujeito pós-colonial reflete-se em muitas linhas do comentário, que emprega uma perspetiva subjetiva e individual para atingir uma dimensão coletiva e nacional:

No centro da praça mais emblemática da cidade, revestida da nacionalista calçada portuguesa nos últimos anos da nossa dominação, encontro um retrato de Mao Tsé-Tung com os seus operários, soldados e camponeses a posar para a recordação duma eufórica Revolução Cultural. Como se a história se apagasse com um simples clique das dezenas de máquinas fotográficas que obsessivamente congelam a memória e ficcionam a felicidade ( $A$ Última Vez Que Vi Macau, 2012, 00:13:28-00:13:58).

As ruas pareciam-me todas iguais. Perdi-me. Pedi explicações, mas ninguém conseguia compreender. Quatro séculos de Portugal em Macau e ninguém fala português (A Última Vez Que Vi Macau, 2012, 00:18:45-00:19:22)

O reencontro frustrado de Guerra da Mata com a sua antiga cidade será um caso de "transnacionalismo epifánico", uma categoria em que "the emphasis", como escreve Mette Hjort (2009, 16), "is on the cinematic articulation of those elements of deep national belonging that overlap with aspects of other national identities to produce something resembling deep transnational belonging”. Outro filme português que poderá entrar nesta categoria é Ganhar a Vida (2001, João Canijo), já que a sua forma e o seu conteúdo partilham elementos de diferentes tradições nacionais: por um lado, a tradição portuguesa, porque o seu relato decorre no interior de uma comunidade de emigrantes portugueses instalada num bairro periférico de Paris; por outro lado, a tradição francesa, porque esse mesmo relato pode ser percebido desde a perspetiva contrária, como um relato de imigrantes dentro do género do cinema de banlieu; e, por último, a tradição europeia do cinema de autor, influenciada nessa altura pelas propostas do movimento cinematográfico dinamarquês Dogma 95, do que João Canijo tira algumas ideias estilísticas relativas à rodagem com câmara digital.

Ganhar a vida é uma das muitas coproduções francoportuguesas que se produzem desde os anos oitenta, pelo menos desde que o produtor Paulo Branco multiplicou a sua atividade cinematográfica entre Lisboa e Paris. Os filmes sucessivamente produzidos pelas suas empresas - Madragoa Filmes, Gemini Films, Clap Filmes, Alfama Films, etc. - são exemplos da categoria "transnacionalismo por afinidade", ou seja, um tipo de coprodução focada, segundo Hjort $(2009,17)$, "on 'the tendency to communicate with those similar to us', with similarity typically being understood in terms of ethnicity, partially overlapping or mutually intelligible languages, and a history of interaction giving rise to shared core values, common practices, and comparable institutions". 
Esta categoria é onde mais filmes portugueses encontram uma dimensão transnacional, porque sabem aproveitar o apoio económico estrangeiro para transformar essas relações de afinidade em sinergias criativas. Neste sentido, Mistérios de Lisboa (2010, Raul Ruiz) é a grande obra-prima do "transnacionalismo por afinidade": trata-se duma coprodução franco-portuguesa realizada por um cineasta chileno que conta uma história, adaptada de vários escritos de um autor clássico português (Camilo Castelo Branco), falada em várias línguas e que decorre por quatro países diferentes - Portugal, França, Itália e Brasil. Qual será então a nacionalidade de Mistérios de Lisboa?

Raul Ruiz é também um dos casos mais claros de cineasta cosmopolita: primeiro começa a filmar no seu país natal, Chile; depois, durante a ditadura de Augusto Pinochet, continua a sua obra no exílio, em França; nestes anos também visita Portugal em várias ocasiões para fazer filmes com Paulo Branco; nos anos noventa emigra pontualmente para Estados Unidos por motivos profissionais; e volta também de modo recorrente ao Chile para lá filmar nos últimos anos da sua vida. Este nomadismo fez com que Ruiz desenvolvesse uma identidade cosmopolita que lhe permitiu entrar e sair de diferentes cinemas nacionais, assim como transmitir, em filmes como Diálogos de exiliados (1975), a situação pessoal dos sujeitos deslocados pela história: indivíduos expatriados, pós-coloniais e pós-nacionais, que devem lidar com a emigração, o exílio e umas sociedades de acolhimento nem sempre tão hospitaleiras como deveriam. Estas pessoas são os protagonistas dos filmes inscritos na categoria do transnacionalismo cosmopolita, que explora "issues relevant to particular communities situated in a number of different national or subnational locations to which the cosmopolitan auteur has a certain privileged access" (Hjort 2009, 20).

A comunidade emigrante de Ganhar a Vida é o sujeito característico do "transnacionalismo cosmopolita", mas há um exemplo mais evidente desta modalidade no cinema realizado em Portugal: a longa saga cabo-verdiana filmada por Pedro Costa a partir de Casa de Lava (1994). Apesar destas populações marginais terem sido historicamente privadas de representação porque não entram no perfil habitual de cidadãos nacionais, a sua perspetiva tornou-se essencial nas últimas décadas para compreender a experiência histórica e cultural das metrópoles ocidentais contemporâneas, como argumenta o teórico indiano Homi K. Bhabha $(1994,6)$ : as nossas sociedades devem assim enfrentar "its postcolonial history, told by its influx of postwar migrants and refugees, as an indigenous or native narrative internal to its national identity".

Os cabo-verdianos de Lisboa são então tão portugueses como os minhotos ou os algarvios, porque encarnam o outro cultural que, como lembra Catherine Russell (1999, 24), sempre fez parte de nós próprios e das nossas nações. Estando consciente desta situação, Costa está há vinte anos a dar voz e visibilidade a esta comunidade, 
lutando para que a sua história seja também parte da história nacional portuguesa: primeiro, Casa de Lava introduziu no cinema português a figura do trabalhador africano emigrante empregado no setor da construção; depois, Ossos (1997) mostrou a morada destes trabalhadores e a sua relação com a cidade; No Quarto da Vanda (2000) ofereceu um relato oral da história dos seus bairros, representados pelas Fontainhas, no preciso momento da sua destruição; Juventude em Marcha (2006) documentou a deslocação da comunidade para um bairro novo, Casal da Boba, onde chegará também com os seus próprios fantasmas; e, por último, Cavalo Dinheiro (2014) explora abertamente a memória histórica da comunidade, uma memória feita de traumas pessoais e laborais, que às vezes pode mesmo inverter os discursos fundacionais da nação portuguesa ${ }^{8}$.

Os intérpretes com quem Costa trabalha desde Ossos - Vanda, Nhurro, Ventura, Lento, Vitalina - têm a virtude de ser, ao mesmo tempo, eles mesmos e todas as pessoas que alguma vez foram como eles: cabo-verdianos, drogados, imigrantes, os párias da história, os ninguém de nenhures. Ventura, por exemplo, representa as vítimas dos processos de globalização económica, mas também aqueles emigrantes capazes de sobreviver à adversidade num ambiente hostil até conseguir melhorar a sua qualidade de vida, como lhe lembra o fantasma de Lento numa das sequências finais de Juventude em Marcha. O sentimento de perda e de dépaysament que experimentam este tipo de personagens nos filmes inscritos no transnacionalismo cosmopolita não é representado "as transitional states on the transnational subject's path to either transcendence or tragedy", como escrevem Elisabeth Erza e Terry Rowden (2006, 7), "but instead as more or less permanent conditions". O seu drama não pode responder a um arco argumental fechado, porque atinge ao conjunto da sua vida: depois do filme acabar, a saudade destes sujeitos permanece fora do ecrã, lá onde vive uma pessoa deslocada.

Sónia, a protagonista de Transe (2006, Teresa Villaverde), sofre também este mesmo destino durante a sua longa viagem através da Europa, desde a Rússia até Portugal, passando por Alemanha e Itália. Vítima das redes de tráfico de pessoas e de exploração sexual, primeiro perderá a sua liberdade, depois a sua identidade e finalmente a sua própria vontade, a sua capacidade de resistência. Este processo é gradual e irreversível, e vem marcado pela passagem de sucessivas fronteiras e pelo emprego de quatro línguas diferentes: russo, alemão, italiano e português. Embora a cineasta e a intérprete protagonista Ana Moreira sejam portuguesas, Transe não se pode inscrever num único

\footnotetext{
${ }^{8} \mathrm{O}$ exemplo mais evidente desta dinâmica seria a experiência dos cabo-verdianos durante o 25 de Abril, refletida tanto em Juventude em Marcha como em Cavalo Dinheiro. Os dois filmes mostram o pânico que viveu durante esses dias esta comunidade ao ser vítima da violência gratuita que os mesmos soldados que lutavam pela liberdade do povo português exerciam contra eles como divertimento noturno.
} 
cinema nacional, nomeadamente porque a natureza do tema abordado e do tratamento escolhido é profundamente transnacional.

A mesma história já foi contada sem sair de Portugal - mesmo sem sair dum único local - em Noite Escura (2004, João Canijo), onde assistimos ao início de um processo similar: o pai de uma família proprietária de uma casa de alterne vende a sua jovem filha - que curiosamente também se chama Sónia - a uma rede de tráfico de pessoas para saldar uma dívida que tem com eles. As dinâmicas internas da família protagonista, como tem analisado Daniel Ribas (2014) na sua tese sobre o cinema de João Canijo, mostram umas características tipicamente portuguesas, mas a casa de alterne está concebida como um não-lugar extraído do seu contexto, que poderia estar em qualquer lugar de Europa, e as mulheres que lá trabalham são, mais uma vez, sujeitos transnacionais condenados ao movimento perpétuo. O filme, desta vez, não foi coproduzido com nenhum outro país, mas mesmo assim a sua história e o seu estilo, como já acontecia no anterior trabalho de Canijo, Ganhar a Vida, apresentam uma clara vocação cosmopolita.

\section{Conclusão}

Pedro Costa, João Canijo, Teresa Villaverde e João Pedro Rodrigues pertencem a uma geração de cineastas que, a partir dos anos noventa, vão ampliar os temas e as personagens abordadas até então pelo cinema português. Esta geração introduziu uma mudança muito significativa no próprio conceito de cinema português, porque soube renovar a sua tradição através de um encontro, inédito e inesperado nessa altura, com o presente e com o real, como explica Tiago Baptista (2009, 320-321):

Poucos filmes, antes destes, pareciam tão ancorados no seu próprio tempo. E poucos, também, tinham demonstrado tamanha indiferença às reflexões sobre a 'portugalidade'. Poucos, em suma, tinham mergulhado tão profundamente no país e, ao mesmo tempo, se tinham distanciado tanto dele. (...) As personagens destes filmes viviam, trabalhavam, sofriam e morriam como pessoas, e não como portugueses. Quando os filmes portugueses mergulharam de cabeça no presente e descobriram tudo o que ele não tinha de especificamente português (e era muito), conseguiram escapar pela primeira vez às armadilhas de um 'cinema nacional'.

Nesse artigo, Baptista chega à conclusão de que "as ideias predominantes sobre o que o 'nosso' país é (ou não é), excluem muito silenciosamente - mas também muito eficazmente - várias outras pessoas, memórias e experiências do que é a vida, o trabalho e o lazer em Portugal" (Ibidem 322). Para inverter esta tendência, a geração de Costa, Canijo, Villaverde e Rodrigues, juntamente com outros cineastas mais jovens, como Miguel Gomes, João Nicolau, João Salaviza 
ou Salomé Lamas, tentam filmar o mundo desde Portugal para assim posicionar Portugal no mundo.

Os seus filmes apresentam as qualidades das formas que Mette Hjort $(2009,15)$ considera mais valiosas do cinema transnacional: em primeiro lugar, "a resistance to globalization as cultural homogenization", porque são filmes realizados desde Portugal e sobre Portugal, isto é, desde as margens da indústria cinematográfica e do sistema mundo, mas com uma clara vocação de abordar problemas universais; e, em segundo lugar, "a commitment to ensuring that certain economic realities associated with filmmaking do not eclipse the pursuit of aesthetic, artistic, social, and political values", porque são filmes exigentes, intransigentes e comprometidos com a sua própria conceção do cinema, incluindo os trabalhos lúdicos e evasivos de Miguel Gomes e João Nicolau.

Todos estes cineastas apelam à inteligência do público e não se envergonham dos seus baixos orçamentos, relativamente ao padrão norte-americano ou mesmo algum europeu, que às vezes funcionam mesmo como estímulos criativos, como acontece em A Última Vez Que Vi Macau e Cavalo Dinheiro - ainda que esta situação não agrade a investigadores como João Maria Mendes, que reclamam uma cultura organizacional mais complexa e diversificada.

Os temas escolhidos, as personagens representadas, as decisões estéticas e as dinâmicas narrativas de uma parte do cinema português contemporâneo refletem de forma direta ou indireta a integração de Portugal no sistema cinematográfico mundial. Não faz sentido, portanto, continuar a pensar o cinema português a partir da diferença, como uma entidade autónoma e isolada que fica à margem destes processos globais. Faz falta, pelo contrário, que os críticos mudem de perspetiva, sobretudo depois da mudança já realizada por muitos cineastas.

\section{BIBLIOGRAFIA}

Baptista, Tiago. 2009. "Nacionalmente correcto: A inveção do cinema português”, Revista Estudos do Século XX, 9: 307-323.

Bhabha, Homi K. 1994. The Location of Culture. Londres: Routledge.

Cunha, Paulo. 2014. "Miguel Gomes, el cinéfilo". Em Jugar com la Memoria. El Cine Portugués en el Siglo XXI, eds. Horacio Muñoz Fernández e Iván Villarmea Álvarez, 108-133. Santander: Shangrila Textos Aparte.

Defoe, Daniel. 1719. Robinson Crusoe. Londres: W. Taylor. 
Desser, David. 2003. "Global Noir: Genre Film in the Age of Transnationalism”. Em Film Genre Reader III, ed Barry Keith Grant, 516-536. Austin: University of Texas Press.

Durovicová, Nataša e Kathleen Newman, eds. 2009. World Cinemas, Transnational Perspectives. Londres e Nova Iorque: Routledge.

Elsaesser, Thomas. 2005. European Cinema. Face to Face with Hollywood. Amsterdão: Amsterdam University Press.

Ezra, Elizabeth e Terry Rowden. 2006. "What Is Transnational Cinema?". Em Transnational Cinema, the Film Reader, ed. Elizabeth Ezra e Terry Rowden, 1-12. Londres e Nova Iorque: Routledge.

Higbee, Will e Song Hwee Lim. 2010. "Concepts of Transnational Cinema: Towards a Critical Transnationalism in Film Studies", Transnational Cinemas 1 (1): 7-21.

Higson, Andrew. 1989. "The Concept of National Cinema", Screen 30 (4): 36-46.

Higson, Andrew. 2006. "The Limiting Imagination of National Cinema”. Em Transnational Cinema, the Film Reader, ed. Elizabeth Ezra e Terry Rowden, 15-25. Londres e Nova Iorque: Routledge.

Hjort, Mette. 2009. "On the Plurality of Cinematic Transnationalism”. Em World Cinemas, Transnational Perspectives, ed. Natasa Durovicova e Kathleen Newman, 12-33. Londres e Nova Iorque: Routledge.

Lotman, Yuri M. 1990. The Universe of the Mind: A Semiotic Theory of Culture. Bloomington e Indianapolis: Indiana University Press.

Lu, Sheldon Hsiao-peng, ed. 1997. Transnational Chinese Cinemas: Identity, Nationhood, Gender. Honolulu: University of Hawaii Press.

Martins, Levi e Miguel Cipriano. 2013. "Luís Urbano (O Som e a Fúria): "Tem de haver uma sociedade secreta entre realizador e produtor”. Em Novas \& Velhas Tendências no Cinema Português Contemporâneo, coord. João Maria Mendes, 343-357. Faro / Lisboa: Centro de Investigação em Artes e Comunicação (CIAC) e Gradiva Publicações.

Mendes, João Maria. 2013. “Objectos únicos e diferentes. Por uma nova cultura organizacional do cinema português contemporâneo". Em Novas \& Velhas Tendências no Cinema Português Contemporâneo, coord. João Maria Mendes, 74-137. Faro / Lisboa: Centro de Investigação em Artes e Comunicação (CIAC) e Gradiva Publicações.

Mendes, João Maria. 2013. "As entrevistas, susas leituras e seu syllabus". Em Novas \& Velhas Tendências no Cinema Português 
Contemporâneo, coord. João Maria Mendes, 501-550. Faro / Lisboa: Centro de Investigação em Artes e Comunicação (CIAC) e Gradiva Publicações.

Nancy, Jean-Luc. 1996. Être singulier pluriel. Paris: Galilée.

Nestingen, Andrew K e Trevor G. Elkington, eds. 2005. Transnacional Cinema in a Global North. Nordic Cinema in Transition. Detroit: Wayne State University Press.

O’Regan, Tom. (2004) 2009. "Cultural Exchange”. Em The Contemporary Hollywood Reader, ed Toby Miller, 500-525. London and New York: Routledge.

Ribas, Daniel. 2014. Retratos de Família - A Identidade Nacional e a Violência em João Canijo. Tese de Doutoramento. Aveiro: Universidade de Aveiro.

Robertson, Roland. 1995. "Glocalization: Time-Space and Homogeneity-Heterogeneity". Em Global Modernities, ed. Mike Featherstone, Scott Lash e Roland Robertson, 25-44. London, Thousand Oaks e New Delhi: SAGE Publications.

Russell, Catherine. 1999. Experimental Ethnography. The Work of Film in the Age of Video. Durham e Londres: Duke University Press.

Shaw, Deborah. 2013. "Deconstructing and Reconstructing 'Transnational Cinema'”. Em Contemporary Hispanic Cinema: Interrogating Transnationalism in Spanish and Latin American Film, ed Stephanie Dennison, 47-66. Woodbridge: Tamesis.

Sousa Dias, Vanessa; Carlos Pereira e Jorge Jácome. 2013. "João Pedro Rodrigues: 'O fundamental é o festival onde o filme é apresentado'". Em Novas \& Velhas Tendências no Cinema Português Contemporâneo, coord. João Maria Mendes, 263-273. Faro / Lisboa: Centro de Investigação em Artes e Comunicação (CIAC) e Gradiva Publicações.

\section{FILMOGRAFIA}

24 City [longa-metragem] Dir. Jia Zhang-ke. Bandai Visual Company / Bitters End / China Resources / Office Kitano / Shanghai Film Group / Xstream Pictures, China / Hong Kong / Japão, 2008. $112 \mathrm{~min}$.

Acto de Primavera [longa-metragem] Dir. Manoel de Oliveira. Portugal, 1963. $94 \mathrm{~min}$

Alamar [longa-metragem] Dir. Pedro González-Rubio. Mantarraya Producciones / Xkalakarma, México, 2009. 73 min. 
Aquele Querido Mês de Agosto [longa-metragem] Dir. Miguel Gomes. O Som e a Fúria / Shellac Films, Portugal / França, 2008. 147 min.

A Cara que Mereces [longa-metragem] Dir. Miguel Gomes. O Som e a Fúria, Portugal, 2004. 108 min.

Casa de Lava [longa-metragem] Dir. Pedro Costa. Madragoa Filmes / Gemini Films / Pandora Filmproduktion, Portugal / França / Alemanha, 1994. $110 \mathrm{~min}$.

Cavalo Dinheiro [longa-metragem] Dir. Pedro Costa. Sociedade Óptica Técnica, Portugal, 2014. 103 min.

Diálogos de exiliados [longa-metragem] Dir. Raúl Ruiz. Chile / França, 1975. $100 \mathrm{~min}$.

Entre les murs [longa-metragem] Dir. Laurent Cantet. Haut et Court / France 2 Cinéma et al., França, 2008. 128 min.

Ganhar a Vida [longa-metragem] Dir. João Canijo. Madragoa Filmes / Gemini Films / Instituto do Cinema, Audiovisual e Multimédia (ICAM) / La Sept-Arte / Radiotelevisão Portuguesa (RTP), Portugal / França, 2001. 115 min.

Hatari! [longa-metragem] Dir. Howard Hawks. Malabar, Estados Unidos, 1962. $157 \mathrm{~min}$

Juventude em Marcha [longa-metragem] Dir. Pedro Costa. Contracosta Produções / Ventura Film / Les Films de L'Etranger / Radiotelevisão Portuguesa (RTP) / Unlimited, Portugal / França / Suíça, 2006. 155 min.

Macao [longa-metragem] Dir. Josef von Sternberg e Nicholas Ray. RKO Radio Pictures, Estados Unidos, 1952. 81 min.

As Mil e Uma Noites: Volumem 1, O Inquieto; Volumem 2, O Desolado; Volumem 3, O Encantado [três longa-metragens] Dir. Miguel Gomes. O Som e a Fúria / Shellac Sud / Komplizen Film / Box Productions et al, Portugal / França / Alemanha / Suíça, 2015. 125 mins. / 131 mins. / 125 mins.

Mistérios de Lisboa [longa-metragem] Dir. Raúl Ruiz. Clap Filmes et al., Portugal / França, 2010. 272 min.

Mogambo [longa-metragem] Dir. John Ford. Metro-Goldwyn-Mayer, Estados Unidos, 1953. $116 \mathrm{~min}$.

No Quarto da Vanda [longa-metragem] Dir. Pedro Costa. Contracosta Produções / Ventura Film / Instituto Português da Arte Cinematográfica e Audiovisual / Pandora Filmproduktion / Televisione Svizzera Italiana / Zweites Deutsches Fernsehen, Portugal / Alemanha / Suíça, 2000. 170 min.

Noite Escura [longa-metragem] Dir. João Canijo. Madragoa Filmes / Gemini Films, Portugal, 2004. 94 min. 
Nós por cá Todos Bem [longa-metragem] Dir. Fernando Lopes. Centro Português de Cinema (CPC), Portugal, 1978. 80 min.

Ossos [longa-metragem] Dir. Pedro Costa. Madragoa Filmes / Gemini Films / Zentropa Productions, Portugal / França / Dinamarca,1997. $94 \mathrm{~min}$.

Out of Africa [longa-metragem] Dir. Sidney Pollack. Mirage Enterprises, Universal Pictures, Estados Unidos, 1985. $161 \mathrm{~min}$.

Paraíso Perdido [longa-metragem] Dir. Alberto Seixas Santos. Animatógrafo / Fundação Calouste Gulbenkian / Instituto Português de Cinema (IPC) / Radiotelevisão Portuguesa (RTP), Portugal, 1995. $90 \mathrm{~min}$.

Le quattro volte [longa-metragem] Dir. Michelangelo Frammartino. Invisibile Film / Ventura Film / Vivo Film / Essential Filmproduktion GmbH et al., Itália / Alemanha / Suíça, 2010. 88 $\min$.

Snow White and the Seven Dwarfs [longa-metragem] Dir. David Hand, William Cottrell, Wilfred Jackson, Larry Morey, Perce Pearce, Ben Sharpsteen. Walt Disney Productions, Estados Unidos, 1937. $83 \mathrm{~min}$.

Tabu [longa-metragem] Dir. Miguel Gomes. O Som e a Fúria / Komplizen Film / Gullane Filmes / Shellac Sud Z et al., Portugal / Alemanha / Brasil / França / Espanha, 2012. 118 min.

Tabu, a Story of the South Seas [longa-metragem] Dir. Friedrich W. Murnau. Murnau-Flaherty Productions, Estados Unidos, 1931. 86 min.

Transe [longa-metragem] Dir. Teresa Villaverde. Madragoa Filmes / Gémini Films / Clap Filmes / Revolver Film / The Hermitage Bridge Studio, Portugal / França / Itália / Rússia, 2006. 126 min.

Todos vós sodes capitáns [longa-metragem] Dir. Óliver Laxe. Zeitun Films, Espanha, 2010. 78 min.

A Ultima Vez Que Vi Macau [longa-metragem] Dir. João Pedro Rodrigues e João Rui Guerra da Mata. Blackmaria / Epicentre Films / Instituto do Cinema e do Audiovisual (ICA), 2012. $82 \mathrm{~min}$.

Vivre sa vie: Film en douze tableaux [longa-metragem] Dir. Jean-Luc Godard. Les Films de la Pléiade / Pathé Consortium Cinéma, França, 1961. 80 min.

The Wizard of $\mathrm{Oz}$ [longa-metragem] Dir. Victor Fleming. MetroGoldwyn-Mayer, Estados Unidos, 1939. $102 \mathrm{~min}$. 